\title{
Sentidos da História atribuídos por jovens em diálogo com aspectos de uma cultura política e histórica emergentes na cultura escolar
}

\author{
Lana M. de C. Siman \\ Herbert de Oliveira Timóteo \\ João Andrade \\ Mariano A. Diniz Filho
}

\section{SciELO Books / SciELO Livros / SciELO Libros}

SIMAN, L.M.C., TIMÓTEO, H.O., ANDRADE, J., and DINIZ FILHO, M.A. Sentidos da História atribuídos por jovens em diálogo com aspectos de uma cultura política e histórica emergentes na cultura escolar. In: CERRI, L.F., ed. Os jovens e a História: Brasil e América do Sul [online]. Ponta Grossa: Editora UEPG, 2018, pp. 85-114. ISBN: 978-85-7798-248-6.

https://doi.org/10.7476/9788577982486.0005.

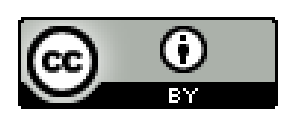

All the contents of this work, except where otherwise noted, is licensed under a Creative Commons Attribution $\underline{4.0 \text { International license. }}$

Todo o conteúdo deste trabalho, exceto quando houver ressalva, é publicado sob a licença Creative Commons Atribição 4.0. 


\section{SENTIDOS DA HISTÓRIA ATRIBUÍDOS POR JOVENS EM DIÁLOGO COM ASPECTOS DE UMA CULTURA POLÍTICA E HISTÓRICA EMERGENTES NA CULTURA ESCOLAR}

Lana M. de C. Siman

Herbert de Oliveira Timóteo

João Andrade

Mariano A. Diniz Filho

\section{UM INÍCIO DE CONVERSA...}

Apreender e analisar a formação dos sentidos da História atribuídos por diferentes jovens ${ }^{1}$ estudantes do primeiro ano do Ensino $\mathrm{Médio}^{2}$, na cidade de Belo Horizonte, pode remeter a variados campos epistemológicos e de pesquisas nas áreas da sociologia, antropologia, filosofia, entre outras. São processos complexos, por vezes, implicados em relações históricas mais amplas, pois que ancoradas nos tempos (HELLER, 1993). E quando se trata de apreendê-los e analisá-los, durante processos do ensinar e aprender História em variados ambientes educativos, outros dialogam com aspectos da cognição e sensibilidades (MIRANDA, 2007; PEREIRA; SIMAN, 2009). Movimentos estes envolvidos em variadas potencialidades, contradições e reveses.

Para a apreensão e análise da formação dos sentidos históricos, supostamente construídos pelos alunos do primeiro ano do Ensino Médio que responderam aos questionários do projeto Os Jovens e a História em março de 2013, tomamos como referência Rüsen (2001; 2010; 2014). Não obstante, neste movimento, comparecem outras experiências vivenciadas pelos jovens estudantes, no caso, as práticas culturais (PEREIRA; SIMAN, 2009), construídas nos âmbitos de uma cultura escolar (FARIA FILHO; VIDAL, 2004), em diálogos com aspectos de uma cultura histórica (ABREU;

\footnotetext{
${ }^{1}$ Para aprofundamento acerca das reflexões e experiências das juventudes, sugerimos as leituras de Dayrell (2013; 2013). Acesso ao observatório da juventude UFMG: <http://observatoriodajuventude. ufmg.br/> e ao observatório jovem da UFF: <http://www.uff.br/observatoriojovem/>.

${ }^{2}$ Atualmente, no Brasil, esta modalidade educativa experiencia múltiplas tensões e controvérsias advindas de movimentos da Sociedade Civil, Estado, Escola e Universidade. Desta forma, podemos caracterizá-la como uma Questão Socialmente Viva (TUTIAUX-GUILON, 2011).
} 
GONTIJO; SOIHET, 2007), criando predisposições favoráveis para lutas de acesso aos bens materiais e simbólicos, contribuindo para a formação de cultura democrática (MOISES, 1992).

As pesquisas acerca dos processos de atribuição de sentidos à História, pelos jovens estudantes do Ensino Médio, podem estar ancoradas em variadas perspectivas, tanto teóricas quanto metodológicas, mas ainda são poucas. De maneira geral, até o momento, temos Hollerbach (2007) e Diniz Filho (2013). No campo, mais especifico, da consciência histórica, com o qual se relaciona a formação de sentido histórico, objeto deste trabalho, temos outras pesquisas e trabalhos realizados, tanto internacionalmente como nacionalmente, entre eles Pais (1999), Barca (2012), Cerri e Molar (2010), Cerri, (2011b), Cerri e Aguirre (2011) e Schimdt (2016a; 2016b) ${ }^{3}$.

Além de contribuir para essa área de estudos, nosso trabalho visa, também, a trazer contribuições analíticas ao projeto Os Jovens e a História ${ }^{4}$. Assim, vamos analisar os sentidos atribuídos à História dados pelos jovens estudantes do Ensino Médio, em duas escolas públicas, nas quais aplicamos os questionários do projeto em março de 2013.

Do conjunto de cinco escolas de Belo Horizonte onde foram aplicados os questionários do projeto Os Jovens e a História, junto aos alunos e professores de História, duas escolas públicas foram escolhidas. Uma das escolas localiza-se em comunidade de alta vulnerabilidade social, e outra na região centro-sul da cidade. A primeira atende jovens de sua localidade; a outra, os jovens provenientes de diferentes territórios desta cidade e de

\footnotetext{
${ }^{3}$ Conforme pesquisa realizada no portal de dissertações e teses da Capes, até o momento, encontramos as duas dissertações. As outras pesquisas e trabalhos encontrados emergem de nossa pesquisa nos sítios eletrônicos de algumas revistas, no campo do ensino de História, e da Educação, entre elas a História Hoje, e Educação (UFSM), exceto o livro de Pais (1999).

${ }^{4}$ Este Projeto de pesquisa, de natureza predominantemente quantitativa, dialoga com o Youth and History, desenvolvido nos países europeus a partir de 1994, com base na rede European Standing Conference of History Teachers Associations (Euroclio). A partir de 2006, tendo em vista contribuir com a construção sociocultural do MERCOSUL, notadamente pesquisando aspectos da consciência histórica dos jovens desse território, pesquisadores latino-americanos inserem-se nesse projeto, realizando uma adequação e reformulação de algumas perguntas do questionário usado no projeto Youth and History, atentando para nossas especificidades sócio-históricas. No Brasil, ele é coordenado pelo pesquisador Luís F. Cerri (GEDHI/UEPG), realizando trabalho conjunto com outros grupos de pesquisa na área do Ensino e Aprendizagem de História, entre eles LABEPEH/CP/FAE/UFMG e POLISMNEMOSINE/PPGE/FAE/UEMG. Para apreensão e compreensão deste projeto, a partir de suas publicações, sobretudo no Brasil, sugerirmos a leitura de Barom (2016).
} 
seu entorno. Ambas as escolas pertencem à rede estadual de ensino do Estado de Minas Gerais tendo, do ponto de vista oficial, normas, legislação e currículos semelhantes. Além disso, nossa escolha por essas duas escolas ocorreu devido à existência, no interior delas, de práticas culturais, sociais e políticas com o engajamento dos jovens. Em uma delas, tais práticas reverberam na comunidade local.

Tendo em vista nosso estudo, selecionamos algumas questões e opções do questionário da pesquisa que foram aplicadas junto aos estudantes e aos professores de História; realizamos algumas visitas exploratórias àquelas duas escolas; e às suas redes sociais de internet. Movimento este que visa a analisar a atribuição de sentidos à História atribuídos pelos jovens, em diálogo com práticas culturais, reinventando a cultura escolar.

Contemporaneamente, sem negligenciar as contradições de uma Educação massificada, a escola tem, cada vez mais, aberto seus portões e salas de aula a várias práticas culturais (FORQUIM, 2001; SIMAN, 2003). É dentro destes complexos contextos da Educação Básica que vamos buscar analisar os sentidos atribuídos, pelos jovens estudantes, à História.

Importante também é ressaltar que tais processos dialogam com variadas experiências na/da sala de aula, nos espaços da escola, e para além dos seus portões. São práticas culturais nas quais os jovens educandos estão inseridos e/ou são, potencialmente, mobilizados pelos docentes e a escola a se engajarem, oportunizando, por vezes, diálogos com uma cultura histórica, política. O trabalho de Schimdt (2016a), em alguns aspectos, potencializa a realizar inferências nesta direção. Uma delas, reafirmar as potencialidades das práticas culturais quando, em diálogo com a vida prática e as carências de orientação dos jovens alunos, proporciona, por vezes, reflexões, questionamentos ou atitudes acerca de aspectos da cultura histórica. Também, provavelmente, iniciar processos, na perspectiva de reinvenção da categoria política, desde o espaço da sala de aula, oportunizando possíveis atribuições de sentidos à História.

Diante do exposto até aqui, trabalhamos com a suposição de que as práticas culturais possibilitam aos jovens estudantes vivenciarem experiências variadas, que contribuem tanto para a formação de uma cultura política 
de participação democrática ${ }^{5}$, como para agirem de maneira temporalmente orientada. Perguntamos como comparecem a aprendizagem e o ensino da História, assim como a adesão a elementos da cultura histórica difundidos em diferentes lugares e meios, tais como museu, filmes, mídias escritas e digitais, na configuração dos sentidos que os jovens atribuem à História, nesses contextos escolares singulares. Perguntamos, ainda, se há presença de indícios que levam a relacionar os sentidos atribuídos à História pelos jovens com o seu agir no presente, com a sua leitura a respeito do passado e com a elaboração que constroem a respeito do futuro. $\mathrm{O}$ conceito de formação de sentido histórico, construído pelo filósofo da História, Jörn Rüsen, tem uma historicidade e impulsiona ao agir humano (WIKLUND, 2008; CERRI, 2011a). Os processos de formação de sentido histórico perpassam, de maneira geral, os trabalhos daquele filósofo da História, em uma perspectiva para além da dimensão instrumental. A formação de sentido estabelece profundo diálogo com aspectos da Consciência histórica, tendo em vista, sobretudo, a reflexão fundada em bases históricas, visando à tomada de decisões mais elaboradas (CERRI, 2011a).

\section{FORMAÇÃO DO SENTIDO HISTÓRICO...}

Visando a apropriarmo-nos do conceito Sentido histórico de Jörn Rüsen, dialogamos, grossíssimo modo, com seus trabalhos (2001; 2010; 2014), ao mesmo tempo estabelecendo interlocução com outros teóricos que também laçam importantes luzes sobre a formação de sentido histórico.

Se o sentido histórico é construído durante os processos da experiência humana, e está implicado em historicidades (HELER, 1993), de acordo com Jörn Rüsen, ele emerge do pensamento histórico cotidiano, dialogando com aspectos de uma memória histórica, com as temporalidades moventes e processos de formação identitária(s), visando a potenciais orientações e a um engajamento ponderado. Em nosso trabalho, buscamos

\footnotetext{
${ }^{5} \mathrm{O}$ conceito de Cultura Política pode ser trabalhado, complementarmente, através da compreensão de dois cientistas políticos: Moisés (1992) e Borba (2005). Aqui, explicitaremos a apropriação de Julian Borba acerca do trabalho de Almond e Verba (1989), construída no livro The Civic Culture. Para aqueles cientistas políticos, Cultura Política “[...] refere-se às orientações especificamente políticas, às atitudes com respeito ao sistema político, suas diversas partes e o papel dos cidadãos na vida pública" (1989 apud BORBA, 2005, p. 148).
} 
analisá-los enquanto formação que se realiza em diálogo com as práticas culturais experienciadas na cultura escolar, emergentes do diálogo com variados ambientes educativos da cidade. Conforme Rüsen (2001, p. 160), a formação de sentido histórico "[...] perpassa todas as dimensões das mais diversas manifestações da vida humana", entre elas, a sala de aula de história e a escola, em suas dimensões reflexivas, comunicativas e sensíveis (MIRANDA, 2007). Este processo, conforme já escrevemos, demanda diálogos com outros campos.

Tendo em vista apreender e analisar aspectos da experiência histórica que compõem a formação de sentidos históricos, e organizar a reflexão acerca deles, Jörn Rüsen organiza uma tipificação dos mesmos. Para tanto, dialoga com dimensões da memória histórica, relações dinâmicas entre as temporalidades e a formação de identidades. Estas dimensões perpassam um diálogo profundo com a existência humana e buscam, na pesquisa historiográfica, fundamentações para construir uma racionalidade comunicativa. Grossíssimo modo, apresentaremos os tipos de sentido por ele elaborados:

- A constituição tradicional de sentido visa a construir argumentação histórica fundada na representação do establishment do mundo e da vida, negligenciando a produção e o papel crítico da historiografia;

- A constituição exemplar de sentido histórico dialoga com a memória histórica visando a buscar exemplos que orientem o presente. A História é compreendida como mestra da vida, História magistra vitae;

- A constituição crítica de sentido é a tentativa de problematizar os sentidos culturalmente influentes, e oportunizar, recorrendo a dimensões da memória histórica, a busca de modelos alternativos, visando a desnaturalizar a naturalidade aparente;

- A constituição genética de sentido histórico pode ser compreendida como um complexo movimento que considera as várias potencialidades de mudança histórica, em uma 
relação dinâmica com as temporalidades, tendo em vista as complexidades das contingências do presente.

Reiterando, todos estes processos estabelecem uma profunda relação com os questionamentos cotidianos, fundando-se em argumentos historiográficos, visando a formações identitárias e mobilização ao agir reflexivo e, por que não, do sensível. Assim sendo, os sentidos não são encontrados em sua forma pura, mas sendo condicionados, condicionando e problematizando ao mesmo tempo (RÜSEN, 2010). Assim, "a formação de sentido pode ser explicitada conceitualmente como a interconexão complexa de quatro atividades mentais: experimentar, interpretar, orientar e motivar" (RÜSEN, 2014, p. 267). Processos estes potencialmente envolvidos com a elaboração de uma "[...] vontade de agir enquanto força motivadora (RÜSEN, 2014, p. 268, grifos nossos)", tendo em vista, entre outros aspectos, a elaboração de expectativas futuras e a formação identitária. Processo este implicado em potencialidades, limites e contradições.

Diante do exposto, compreendemos ser fundamental atentarmo-nos às múltiplas práticas culturais construídas e experienciadas pelos jovens estudantes do Ensino Médio, sobretudo quando se trata de analisarmos os sentidos, atribuídos por estes jovens alunos, à História. Não obstante, estes processos demandam intercâmbios com outros campos epistemológicos.

\section{DIALOGANDO COM OUTROS CAMPOS...}

Apreender e analisar, dentro do escopo metodológico deste projeto, os sentidos atribuídos à História pelos jovens alunos do primeiro ano do Ensino Médio nas escolas públicas selecionadas, demanda diálogos com aspectos da cultura escolar, histórica, política e as práticas culturais.

Assim, é fundamental dialogarmos com aquilo que se faz entre os muros da escola e dialogar com as normas, fazeres e experiências nas quais vários sujeitos outros estão implicados com aquelas práticas, suas potencialidades, tensões e reveses, ou seja, a cultura escolar (LUCIANO; VIDAL, 2004). Desse fazer entre os muros da escola emergem diálogos com variadas experiências sociais, culturais e políticas experienciadas fora da escola e a partir das contingências nas quais estão inseridos, ou seja, a partir de uma 
cultura histórica (ABREU; GONTIJO; SOIHET, 2007), possibilitando, aos sujeitos, elaborarem sua consciência temporal. Outro conceito fundamental, que possibilita compreender aspectos destes movimentos, é o da cultura política. Na perspectiva do cientista político Jose A. Moisés, há um consenso acerca dele, no qual se envolve "[...] a generalização de um conjunto de valores, orientações e atitudes políticas entre diferentes segmentos em que se divide o mercado político e resulta tanto dos processos de socialização, como da experiência política concreta dos membros da comunidade [...]" (MOISÉS, 1992, p. 7). Todas estas experiências e outros fazeres educativos não estão reduzidos ao espaço escolar, dialogam com outros lugares do entorno da escola e da cidade. Em outras palavras, são aquilo que denominamos como Práticas Culturais e políticas, nas quais estão implicados diversos educadores, no ambiente escolar e não escolar, visando a construir processos de ensinar e aprender, em que as múltiplas dimensões dos sentidos e da cognição são, potencialmente, mobilizadas (SIMAN; MIRANDA, 2011; PEREIRA; SIMAN, 2013). Explicitados nossos conceitos, vamos ao diálogo com nossa metodologia, visando a analisar os sentidos atribuídos à História pelos jovens estudantes do primeiro ano do Ensino Médio.

\section{DIÁLOGOS METODOLÓGICOS...}

A escolha das questões e opções oferecidas por cada uma delas levou em conta a natureza do enquadramento teórico que se está propondo, assim como as reflexões de Cerri (2011b) acerca dos seguintes aspectos: atenção à diversidade de questões dos questionários; as opções são elaboradas usando narrativas, predominantemente, de bases decisionais; o aproveitamento dos dados coletados é feito com softwares de estatística; os processos de formação de sentido histórico podem se realizar no espaço escolar e não escolar; a metodologia quantitativa é apenas uma das abordagens acerca desses processos.

Bom ressaltar que, em nosso caso, trata-se de uma compreensão construída com base em uma análise estatística descritiva ${ }^{6}$. Assim,

\footnotetext{
${ }^{6}$ Acerca desta abordagem, consideramos as reflexões construídas pelo pesquisador Luís F. Cerri, acerca dos usos das estatísticas do projeto Jovens e a História para a construção dos artigos, neste livro, durante o VII Seminário Nacional Didática da História, realizado na Universidade Estadual de Ponta Grossa, no período de 30/11 a 02/12/2016. Referenciamo-nos, também, em Cerri (2011b).
} 
priorizamos, dentro do questionário dos alunos, a atribuição de sentidos à História manifestada por eles na questão 1 (O que significa a história para você?). De outro lado, tendo em vista o aspecto sociocultural da aula (MIRANDA, 2007) e a dimensão relacional, implicada no movimento de formação de sentidos históricos (RÜSEN, 2010), selecionamos a questão 13 (O que normalmente acontece durante as aulas de História?) do questionário dos professores ${ }^{7}$. Em ambas, escolhemos algumas opções que, estatisticamente, evidenciavam uma tendência central, em termos percentuais ${ }^{8}$, mensurados no questionário do projeto, com base na escala Likert $^{9}$, ou escala de atitudes (CERRI, 2011b). Processo este que visa a analisar os sentidos atribuídos pelos jovens educandos à História, no plano nacional e em Belo Horizonte. No caso das análises das escolas públicas, em Belo Horizonte buscamos, dentro do escopo metodológico deste estudo, relacionar os aspectos estatísticos mencionados anteriormente com nossas incursões exploratórias, tanto às escolas quanto às suas redes sociais na internet.

\section{OS DADOS NACIONAIS E DA CIDADE DE BELO HORIZONTE: FORMANDO SENTIDOS HISTÓRICOS}

Tendo em vista as questões apresentadas anteriormente, realizamos o recorte de algumas opções, levando em conta sua tendência central evidenciada pelas porcentagens das alternativas. Com esses dados, analisamos os sentidos atribuídos, por estes sujeitos estudantes, à História, tanto no plano nacional como na cidade de Belo Horizonte. Em seguida, realizamos

\footnotetext{
${ }^{7}$ Conforme sugestões do pesquisador Luís F. Cerri, no decorrer de todo o texto explicitaremos, entre parênteses, para fins de maior clareza, a qual questionário pertence cada uma das questões usadas: Questão 1 (Questionário dos alunos); Questão 13 (Questionário dos professores). Depois, levando em conta aspectos de forma, durante a análise empírica dos dados, tanto da escola pública de periferia quanto da escola pública central, a questão 13 (Questionário dos professores) e suas opções selecionadas para análise terão seus dados apresentados no corpo do texto, sem uso de tabelas.

${ }^{8}$ Escolha realizada após diálogos com o Pesquisador- Coordenador do projeto, tendo em vista, também, nosso estudo. Dados reproduzidos a partir das tabelas (porcentagens válidas) geradas do programa SPSS.

${ }^{9} \mathrm{~A}$ escala de Likert ou escala de atitudes oportuniza, ao respondente, marcar sua concordância ou discordância, graduada em cinco níveis (discordo totalmente, discordo, indiferente, concordo, concordo plenamente), de acordo com as alternativas para cada afirmação do questionário. Essas respostas são traduzidas numericamente, gerando médias e outras sínteses estatísticas que possibilitam visualizar um quadro geral representativo para cada questão.
} 
uma maior verticalização acerca daquele processo nas escolas selecionadas em Belo Horizonte, levando em conta, também, nossas visitas exploratórias.

Desta forma, na questão 1 (Questionário dos alunos), evidenciada na tabela 1, abaixo, em certa medida podemos nos aproximar da percepção do aluno, quanto aos sentidos que atribui à História. Sentidos estes, por vezes, tácitos (PEREIRA, 2003). Podemos observar, as tendências predominantes estão manifestas nas seguintes opções e alternativas, com suas respectivas medidas percentuais: 1f, com a alternativa Mais ou menos obtendo 23,0\%; Concordo, 42,8 \%; e Concordo totalmente, 22,7\%; 1h, Mais ou menos, 25,7\%, Concordo, 40,4\%, Concordo totalmente, 20,7\%; 1b, Mais ou menos, 36,8\%, Concordo, 36,8\%, Concordo totalmente, 10,6\%. Vejamos a tabela 1.

Tabela 1 - Questão 1: O que significa a história para você? (Estudantes do Brasil)

\begin{tabular}{|c|c|c|c|c|c|c|}
\hline &  &  & 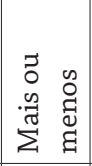 & 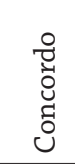 & 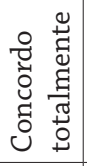 & 胥 \\
\hline 1a. Uma matéria da escola e nada mais. & 31,4 & 36,4 & 21,3 & 8,1 & 2,8 & 100 \\
\hline $\begin{array}{l}\text { 1b. Uma fonte de coisas interessantes que } \\
\text { estimula minha imaginação. }\end{array}$ & 3,3 & 12,5 & 36,8 & 36,8 & 10,6 & 100 \\
\hline $\begin{array}{l}\text { 1c. Uma possibilidade para aprender com os } \\
\text { erros e acertos dos outros. }\end{array}$ & 6,1 & 16,0 & 34,5 & 33,0 & 10,5 & 100 \\
\hline $\begin{array}{l}\text { 1d. Algo que já morreu e passou e que não tem } \\
\text { nada a ver com a minha vida. }\end{array}$ & 43,1 & 33,8 & 12,7 & 6,6 & 3,8 & 100 \\
\hline $\begin{array}{l}\text { 1e. Um número de exemplos que ensinam o } \\
\text { que é certo e o que é errado, o que é bom e o } \\
\text { que é mau. }\end{array}$ & 9,2 & 24,3 & 40,9 & 21,0 & 4,5 & 100 \\
\hline $\begin{array}{l}\text { 1f. Mostra o que está por trás da maneira } \\
\text { de viver no presente e explica os problemas } \\
\text { atuais. }\end{array}$ & 3,7 & 7,7 & 23,0 & 42,8 & 22,7 & 100 \\
\hline 1g. Um amontoado de crueldades e desgraças. & 29,2 & 37,3 & 23,3 & 7,7 & 2,5 & 100 \\
\hline $\begin{array}{l}\text { 1h. Uma forma de entender a minha vida como } \\
\text { parte das mudanças na história. }\end{array}$ & 4,7 & 8,5 & 25,7 & 40,4 & 20,7 & 100 \\
\hline
\end{tabular}

Fonte: dados do Projeto Jovens e a História (2013). Elaborada pelos autores.

Atentando-nos aos mais de $40 \%$ obtidos no score para as alternativas Concordo nas opções $1 \mathrm{f}$ e $1 \mathrm{~h}$; e os $36,8 \%$ para a mesma alternativa, na opção $1 \mathrm{~b}$, supomos que os jovens estudantes tendem a atribuir um sentido à 
História implicado às tensões, sensibilidades, e por que não continuidades, relacionadas a outras temporalidades, com algum impacto em sua vida cotidiana. Estariam os jovens estudantes brasileiros tendendo a superar o presenteísmo, tal como Hobsbawm (1995) refletiu sobre os jovens? Talvez... Do olhar mais próximo à sensibilidade dos jovens estudantes, vamos à questão 13 (Questionário dos professores). Dito isto, encaminhamos, agora, para aquilo que os professores de História tenderam, estatisticamente, quanto a "o que normalmente acontece durante as aulas de história (grifos nossos)?" Em certa medida, estes aspectos dialogam com o movimento de atribuição de sentidos à História. Observemos, abaixo, os dados, da questão 13 (Questionário dos professores) no plano nacional:

Tabela 2 - Questão 13: O que normalmente acontece em durante as aulas de história?

\begin{tabular}{|c|c|c|c|c|c|c|}
\hline & 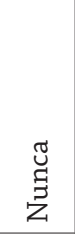 & 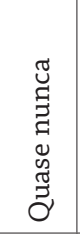 & $\begin{array}{l}\stackrel{\infty}{N} \\
\stackrel{D}{\infty} \\
\infty \\
\infty\end{array}$ & 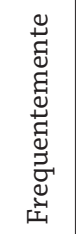 & 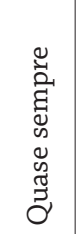 & $\stackrel{\text { Tే }}{0}$ \\
\hline $\begin{array}{l}\text { 13a. Os estudantes ouvem as minhas exposições } \\
\text { sobre o passado. }\end{array}$ & 0,4 & 1,4 & 21,8 & 48,8 & 27,7 & 100 \\
\hline $\begin{array}{l}\text { 13b. Os alunos são informados do que foi bom ou } \\
\text { mau, certo ou errado na História. }\end{array}$ & 15,7 & 12,9 & 23,2 & 31,8 & 16,4 & 100 \\
\hline $\begin{array}{l}\text { 13c. Eles discutem diferentes explicações sobre o } \\
\text { que aconteceu no passado }\end{array}$ & 0,0 & 4,9 & 36,0 & 42,7 & 16,4 & 100 \\
\hline $\begin{array}{l}\text { 13d. Eles pesquisam diversas fontes históricas: } \\
\text { documentos, fotografias, figuras, mapas. }\end{array}$ & 1,1 & 6,0 & 36,7 & 39,6 & 16,6 & 100 \\
\hline 13e. Eles recordam e reinterpretam a História. & 0,4 & 14,0 & 51,9 & 24,2 & 9,5 & 100 \\
\hline $\begin{array}{l}\text { 13f. Eles ouvem fitas, CD's ou vemos filmes e vídeos } \\
\text { sobre História. }\end{array}$ & 0,7 & 4,2 & 44,4 & 35,9 & 14,8 & 100 \\
\hline $\begin{array}{l}\text { 13g. Eles usam livros escolares, apostilas ou algum } \\
\text { outro material (fotocópia). }\end{array}$ & 0,0 & 1,8 & 9,5 & 45,6 & 43,1 & 100 \\
\hline $\begin{array}{l}\text { 13h. Eles participam de atividades em grupo: } \\
\text { encenações de teatro, visitas a museus, projetos } \\
\text { com a comunidade. }\end{array}$ & 3,5 & 23,0 & 36,2 & 24,8 & 12,4 & 100 \\
\hline
\end{tabular}

Fonte: dados do Projeto Jovens e a História (2013). Elaborada pelos autores. 
Na questão 13 (Questionário dos professores), escolhemos as seguintes opções, com suas alternativas e medidas percentuais: $13 \mathrm{~g}$, Às vezes (9,5\%), Frequentemente (45,6\%), Quase sempre (43,1\%); 13a, Às vezes (21,8\%), Frequentemente (48,8\%), Quase sempre (27,7\%); e 13c, com Às vezes (36,0\%), Frequentemente (42,7\%), Quase sempre (16,4\%). Não podemos desprezar as tendências percentuais manifestas na alternativa Às vezes, nas opções $13 \mathrm{f}$ e $13 \mathrm{~h}$. Diante destas tendências percentuais manifestas através das opções e alternativas marcadas pelos professores de História, é possível pensar que o uso de textos didáticos diversos, discussões acerca de aspectos do passado e, não menos importante, aspectos das práticas culturais, poderiam potencializar o movimento de atribuição de sentidos à História, pelos jovens educandos.

Pelos dados até aqui analisados, supomos que os jovens estudantes do Ensino Médio tendem a atribuir sentidos críticos e, por vezes, tradicionais à História, pois, conforme Rüsen (2010), diferentes sentidos podem coexistir em um mesmo grupo social. Tendo apresentado, grosso modo, um panorama acerca da atribuição de sentidos à História, pelos jovens alunos no plano nacional, deslocamo-nos a um processo análogo, agora, na cidade de Belo Horizonte.

Em Belo Horizonte, na questão 1 (Questionário dos alunos), apresentada logo abaixo, na tabela 3 , selecionamos as seguintes opções, com suas respectivas tendências percentuais: 1 f, temos as alternativas Mais ou menos (23,7\%), Concordo (50,5\%), e Concordo totalmente (20,4\%); 1 h com Mais ou menos (31,2\%), Concordo (44,1\%), Concordo totalmente (17,2\%); 1b, Mais ou menos (42,4\%), Concordo (43,5\%), Concordo totalmente (7,6\%). Observemos a tabela 3 . 
Tabela 3 - Questão 1 (Questionário dos alunos) - O que significa a História para você?

\begin{tabular}{|c|c|c|c|c|c|c|}
\hline &  & 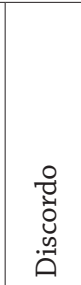 & 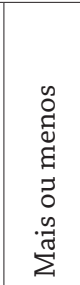 & 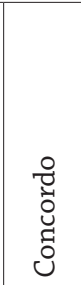 &  & $\stackrel{7 \pi}{0}$ \\
\hline 1a. Uma matéria da escola e nada mais. & 32,3 & 46,2 & 18,3 & 1,1 & 2,2 & 100 \\
\hline $\begin{array}{l}\text { 1b. Uma fonte de coisas interessantes que estimula } \\
\text { minha imaginação. }\end{array}$ & 3,3 & 3,3 & 42,4 & 43,5 & 7,6 & 100 \\
\hline $\begin{array}{l}\text { 1c. Uma possibilidade para aprender com os erros e } \\
\text { acertos dos outros. }\end{array}$ & 5,4 & 16,3 & 35,9 & 29,3 & 13,0 & 100 \\
\hline $\begin{array}{l}\text { 1d. Algo que já morreu e passou e que não tem nada } \\
\text { a ver com a minha vida. }\end{array}$ & 51,6 & 29,0 & 9,7 & 6,5 & 3,2 & 100 \\
\hline $\begin{array}{l}\text { 1e. Um número de exemplos que ensinam o que é } \\
\text { certo e o que é errado, o que é bom e o que é mau. }\end{array}$ & 19,4 & 25,8 & 29,0 & 20,4 & 5,4 & 100 \\
\hline $\begin{array}{l}\text { 1f. Mostra o que está por trás da maneira de viver } \\
\text { no presente e explica os problemas atuais. }\end{array}$ & 2,2 & 3,2 & 23,7 & 50,5 & 20,4 & 100 \\
\hline 1g. Um amontoado de crueldades e desgraças. & 41,8 & 41,8 & 11,0 & 3,3 & 2,2 & 100 \\
\hline $\begin{array}{l}\text { 1h. Uma forma de entender a minha vida como } \\
\text { parte das mudanças na História. }\end{array}$ & 1,1 & 6,5 & 31,2 & 44,1 & 17,2 & 100 \\
\hline
\end{tabular}

Fonte: dados do Projeto Jovens e a História (2013). Elaborada pelos autores.

Arriscaríamos afirmar que podemos pensar que os jovens estudantes tendem a perceber a História a partir de aspectos sensíveis do seu presente, implicados na relação com aspectos de outras temporalidades. Conforme veremos abaixo, na questão 13 (Questionário dos professores), supomos que as práticas culturais, emergentes na/da cultura escolar, potencializem estes processos. A respeito destes movimentos, o que pode informar a questão 13, do questionário dos professores?

$\mathrm{Na}$ questão 13 (Questionário dos professores), escolhemos as seguintes opções, com suas alternativas e tendências percentuais: 13a, Frequentemente (83,3\%), Quase sempre (16,7\%); 13c, com Às vezes (16,7\%), Frequentemente (83,3\%), e 13g, Frequentemente (66,7\%) e Quase sempre (16,7\%). Não obstante, nesta cidade, chamamos atenção para a opção 13h, na qual as alternativas Às vezes e Frequentemente comparecem com 33,3\% e $50 \%$, respectivamente. Observando os dados das opções da questão 13 
(Questionário dos professores), enunciados acima e evidenciados na tabela 4, abaixo, pode-se afirmar que aspectos dialógicos, mediados por variados textos didáticos, e dimensões das práticas culturais experienciadas no âmbito da cultura escolar, em Belo Horizonte, comparecem, em alguma medida, com os processos de atribuição de sentidos à História pelos jovens estudantes do primeiro ano do Ensino Médio.

Tabela 4 - Questão 13 (Questionário dos professores) - O que normalmente acontece em durante as aulas de História?

\begin{tabular}{|c|c|c|c|c|c|c|}
\hline & 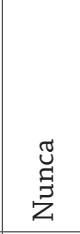 &  & $\begin{array}{l}\mathscr{D} \\
\mathbb{N} \\
\stackrel{8}{0} \\
\infty\end{array}$ & 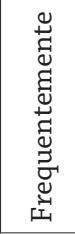 & 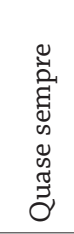 & $\stackrel{\text { तే }}{0}$ \\
\hline $\begin{array}{l}\text { 13a. Os estudantes ouvem as minhas exposições } \\
\text { sobre o passado }\end{array}$ & 0,0 & 0,0 & 0,0 & 83,3 & 16,7 & 100 \\
\hline $\begin{array}{l}\text { 13b. Os alunos são informados do que foi bom ou } \\
\text { mau, certo ou errado na História }\end{array}$ & 33,3 & 33,3 & 0,0 & 16,7 & 16,7 & 100 \\
\hline $\begin{array}{l}\text { 13c. Eles discutem diferentes explicações sobre o } \\
\text { que aconteceu no passado }\end{array}$ & 0,0 & 0,0 & 16,7 & 83,3 & 0,0 & 100 \\
\hline $\begin{array}{l}\text { 13d. Eles pesquisam diversas fontes históricas: } \\
\text { documentos, fotografias, figuras, mapas. }\end{array}$ & 16,7 & 0,0 & 33,3 & 50,0 & 0,0 & 100 \\
\hline 13e. Eles recordam e reinterpretam a História. & 0,0 & 0,0 & 33,3 & 66,7 & 0,0 & 100 \\
\hline $\begin{array}{l}\text { 13f. Eles ouvem fitas, CD’s ou vemos filmes e vídeos } \\
\text { sobre História. }\end{array}$ & 16,7 & 0,0 & 50,0 & 33,3 & 0,0 & 100 \\
\hline $\begin{array}{l}\text { 13g. Eles usam livros escolares, apostilas ou algum } \\
\text { outro material (fotocópia) }\end{array}$ & 0,0 & 16,7 & 0,0 & 66,7 & 16,7 & 100 \\
\hline $\begin{array}{l}\text { 13h. Eles participam de atividades em grupo: } \\
\text { encenações de teatro, visitas a museus, projetos } \\
\text { com a comunidade. }\end{array}$ & 0,0 & 16,7 & 33,3 & 50,0 & 0,0 & 100 \\
\hline
\end{tabular}

Fonte: dados do Projeto Jovens e a História (2013). Elaborada pelos autores.

Em Belo Horizonte, realizado este panorama estatístico descritivo quanto aos dados da questão 1 (Questionário dos alunos) e da questão 13 (Questionário dos professores), supomos haver uma razoável tendência à atribuição de sentidos tradicionais e, por vezes, críticos à História, por parte dos jovens alunos.

Vamos, agora, verticalizar estas apreensões e análises, tendo em vista as escolas selecionadas em Belo Horizonte. 


\section{SENTIDOS HISTÓRICOS EM FORMAÇÃO: ESCOLA, JOVENS ESTUDANTES, PROFESSORES DE HISTÓRIA E A CIDADE FAZENDO-SE...}

Vamos analisar mais detidamente, agora, nas escolas selecionadas, os sentidos da História atribuídos por jovens alunos, em diálogo com aspectos de uma cultura política e histórica emergentes na cultura escolar. Para tanto, situamos a escola pública de periferia, a pública central em diálogos com algumas questões e opções do projeto Os Jovens e a História, cotejando com nossas observações exploratórias junto às escolas e suas redes sociais na internet.

A escola pública de periferia ${ }^{10}$ localiza-se em território (SANTOS, 1994) de alta vulnerabilidade social, na região sul da cidade. Esse território é marcado pela pouca presença e atuação do Estado. Nas últimas décadas, devido à atuação de vários movimentos sociais e culturais, essa situação vem se revertendo paulatinamente ${ }^{11}$. Segundo nossas observações exploratórias, mais especificamente acessando as redes sociais da escola em tela, observamos o engajamento ponderado de alguns de seus professores, direção, estudantes e pedagogos junto àqueles movimentos, tendo em vista seu projeto político-pedagógico. Além deste engajamento ponderado, comparecem à sua cultura escolar variadas práticas culturais: teatros; radio web $^{12}$; visita a museus e outros ambientes educativos da cidade. Ilustram esses movimentos realizados por essa escola as práticas culturais das ilustrações:

\footnotetext{
${ }^{10}$ As análises acerca desta escola são feitas tendo em vista observações exploratórias realizadas anteriormente e no dia da aplicação dos questionários do projeto Os Jovens e a História. Foram realizadas, também, visando à realização deste trabalho de pesquisa, observações exploratórias durante o início do ano letivo de 2017 e em suas redes sociais na internet. Acerca da escola pública central, além de processos análogos à escola pública de periferia, consultamos dissertações existentes sobre ela.

${ }^{11}$ Informações colhidas através de conversas informais junto a professores, alunos e lideranças comunitárias desde o período de aplicação dos questionários do projeto "Os Jovens e a História" nesta escola.

${ }^{12}$ Conforme vídeo gravado com prévia autorização dos estudantes para uso neste artigo:
} 
Figura 1 - Apresentação de peça teatral

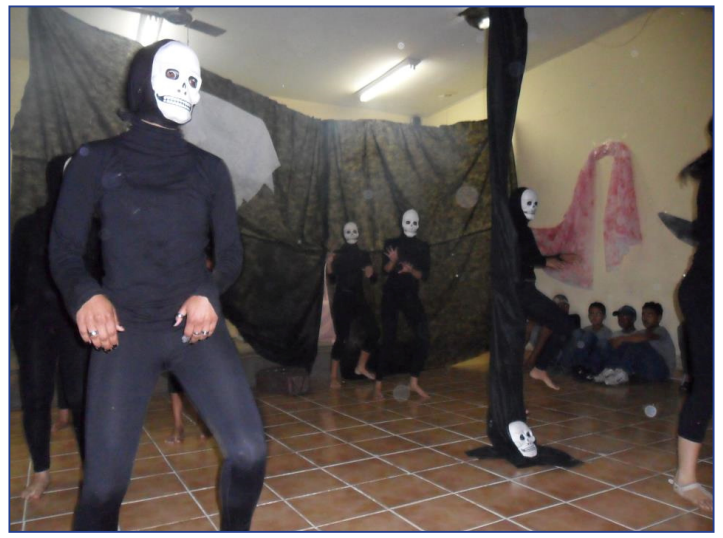

Fonte: Facebook da E. E. Coração Eucarístico. Postada em 14 nov. 2012.

Figura 2 - Leitura na praça



Fonte: Facebook da E.E. Coração Eucarístico. Postada em 15 nov. 2012.

Estas e outras práticas, como a realização de trabalho de campo ao acampamento Eliana Silva (01/12/12), e visita ao instituto Yorubá (24/11/12), por ocasião do projeto Semana da Consciência Negra permitem inferir que elas potencializariam relações mais sensíveis dos estudantes a múltiplos aspectos, e aprendizagens a uma cultura histórica e política. Estas ações no presente, em lugares da cidade (TUAN, 1983) e no âmbito da cultura escolar podem suscitar levantamento de questões e problemas, por vezes por eles mesmos experienciados, em sala de aula, ou em outros ambientes escolares e não escolares. Conforme observamos, nesta escola há 
um razoável comparecimento dos estudantes, professores e direção junto a estas práticas culturais, debates e outros movimentos em sua cultura escolar. Tendo situado esta escola e explicitado aspectos observados no âmbito de sua cultura escolar, passamos agora a dialogar com os dados do projeto de pesquisa Os Jovens e a História. Vejamos, então, a tabela 5.

Tabela 5 - Questão 1 (Questionário dos alunos) - O que significa a História para você?

\begin{tabular}{|c|c|c|c|c|c|c|}
\hline & 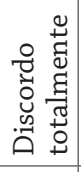 & 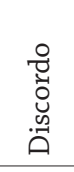 & 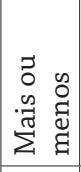 & 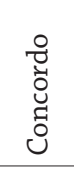 & 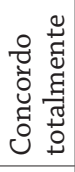 & 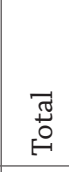 \\
\hline 1a. Uma matéria da escola e nada mais. & 25,0 & 57,1 & 17,9 & 0,0 & 0,0 & 100 \\
\hline $\begin{array}{l}\text { 1b. Uma fonte de coisas interessantes que estimula } \\
\text { minha imaginação. }\end{array}$ & 3,6 & 0,0 & 35,7 & 57,1 & 3,6 & 100 \\
\hline $\begin{array}{l}\text { 1c. Uma possibilidade para aprender com os erros e } \\
\text { acertos dos outros. }\end{array}$ & 7,4 & 11,1 & 48,1 & 25,9 & 7,4 & 100 \\
\hline $\begin{array}{l}\text { 1d. Algo que já morreu e passou e que não tem nada } \\
\text { a ver com a minha vida. }\end{array}$ & 25,0 & 42,9 & 17,9 & 10,7 & 3,6 & 100 \\
\hline $\begin{array}{l}\text { 1e. Um número de exemplos que ensinam o que é } \\
\text { certo e o que é errado, o que é bom e o que é mau. }\end{array}$ & 3,6 & 21,4 & 35,7 & 32,1 & 7,1 & 100 \\
\hline $\begin{array}{l}\text { 1f. Mostra o que está por trás da maneira de viver } \\
\text { no presente e explica os problemas atuais. }\end{array}$ & 3,6 & 3,6 & 32,1 & 46,4 & 14,3 & 100 \\
\hline 1g. Um amontoado de crueldades e desgraças. & 22,2 & 59,3 & 14,8 & 3,7 & 0,0 & 100 \\
\hline $\begin{array}{l}\text { 1h. Uma forma de entender a minha vida como } \\
\text { parte das mudanças na história. }\end{array}$ & 0,0 & 3,6 & 28,6 & 42,9 & 25,0 & 100 \\
\hline
\end{tabular}

Fonte: dados do Projeto Jovens e a História (2013). Elaborada pelos autores.

Atentando-nos às alternativas marcadas nas opções $1 \mathrm{~h}, 1 \mathrm{f}$ e $1 \mathrm{~b}$, observamos que a alternativa Concordo recebe os maiores escores percentuais. Supomos poder depreender destes dados que os jovens estudantes teriam uma provável tendência a atribuir sentidos à História, levando em conta aspectos das relações sociais, culturais e das tensões aí implicadas, expressando suas sensibilidades. Evidenciam estes aspectos os enunciados destas opções, como aquela da opção $1 \mathrm{f}$ "Mostra o que está por trás da maneira de viver no presente e explica os problemas atuais" (grifos nossos). Em alguma medida, podemos depreender dela uma certa relação dinâmica com as temporalidades, oportunizada pela relação com a memória histórica, 
nos termos de Rüsen, em sala de aula, e/ou durante práticas culturais, nos âmbitos da cultura escolar, conforme apreendemos durante nossas observações exploratórias. Outro aspecto a ser considerado, também na tabela 5, são as tendências percentuais às alternativas Mais ou menos e Concordo, evidenciadas nas opções 1e e 1c. Desta forma, supomos não ser desprezível considerar os aspectos dos enunciados destas opções, “[...] exemplos que ensinam [...]", e "Uma possibilidade de aprender com os erros e acertos dos outros" (grifos nossos), que mobilizaram estes jovens alunos. Potencialmente, as práticas culturais são oportunizadoras a estas experiências relacionais, que tocam dimensões do agir e do sensível, mobilizando a aspectos da cognição histórica (MIRANDA; SIMAM, 2011). Isto posto, atentamos, agora, a outro movimento que comparece no processo de atribuir sentidos à História, pelos Jovens alunos, e os fazeres do professor de História desta escola - tendo em vista o aspecto social da aula (MIRANDA, 2007) - observados através da questão 13 (Questionário dos professores).

A alternativa marcada pelo professor de História ${ }^{13}$ nas opções da questão 13 (Questionário dos professores) foi a Frequentemente. Levando em conta as tendências percentuais da questão 1 (Questionário dos alunos), acima, em suas opções 1h, 1f, 1b, 1e e 1c selecionamos, na questão 13 (Questionário dos professores), as opções 13g (Eles usam livros escolares, apostilas ou algum outro material (fotocópia)), 13a (Os estudantes ouvem as minhas exposições sobre o passado), 13h (Eles participam de atividades em grupo: encenações de teatro, visitas a museus, projetos com a comunidade), e $13 f$ (Eles ouvem fitas, cd's ou vemos filmes e vídeos sobre história), como aquelas que, supostamente, potencializam as tendências expressas na referida questão do questionário dos alunos, quanto à atribuição de sentidos à História. Em certa medida, nossas observações exploratórias corroboraram esse processo. Conforme analisamos acima, nesta escola há um razoável engajamento ponderado naquilo que tange à realização de encontros com a

\footnotetext{
${ }^{13} \mathrm{O}$ professor de História respondente deste questionário, em 2013, era designado. Tinha um contrato de trabalho temporário na rede estadual de Educação de Minas Gerais, ou seja, suas condições de trabalho eram precárias (OLIVEIRA, 2004). Situação que ainda está longe de ver solucionada. Destacamos, ainda, a necessidade de superarmos, nas políticas públicas de Educação, a cultura do aulismo e, concomitantemente, a necessidade irmos além da lei 11.738/08 (BRASIL, 2008b), e implantarmos 50\% da prática docente para pesquisa/preparação nas escolas (OLIVEIRA, 2004; DINIZ-FILHO, 2013).
} 
comunidade, trabalhos de campo junto a ocupações urbanas, visita a lugares da cidade e práticas culturais referentes à lei 11645/08 (BRASIL, 2008a), realização de peças teatrais sobre temáticas contemporâneas. No que tange à relação com a comunidade do seu entorno, observamos a participação de adultos e idosos em variadas destas práticas culturais no âmbito da escola, reinventando a cultura escolar. Como exemplo observado junto às redes sociais ${ }^{14}$ desta escola, citamos a realização de uma roda de conversa, em 15 de novembro de 2012, com uma idosa relatando aspectos de sua experiência de vida para jovens alunos do Ensino Médio. Novamente, nossas observações contribuem para evidenciar aspectos marcados na questão 13 (Questionário dos professores), nas opções 13b (Os alunos são informados do que foi bom ou mau, certo ou errado na história), $13 \mathrm{f}$ (Eles ouvem fitas, cd's ou vemos filmes e vídeos sobre história), e 13h (Eles participam de atividades em grupo: encenações de teatro, visitas a museus, projetos com a comunidade) pelo professor de História desta escola. Estes fazeres podem, em alguns aspectos, contribuir com a tendência central observada na questão 1 (Questionário dos alunos), nas opções 1e e 1c, às alternativas Mais ou menos, e Concordo, conforme se pode evidenciar na tabela 5 (Questionário dos alunos), acima. Supomos, assim, que o professor de História, a partir da sala de aula, mobiliza os jovens estudantes a algumas dimensões do agir, tendo em vista exemplos que emergem das práticas culturais experienciadas na cultura escolar, quando atenta ao "[...] que foi bom ou mau, certo ou errado na história”. Não obstante, estes aspectos podem ser aventados, também, enquanto "[...] usam livros escolares, apostilas ou algum outro material (fotocópia)" (grifos nossos).

Assim, levando em conta nossas observações exploratórias, as tendências expressas na questão 1 (Questionário dos alunos), na questão 13 (Questionário dos professores), e suas potenciais relações já sinalizadas, pode ser possível pensar no movimento de atribuição de sentidos à História considerando os seguintes aspectos: usos dos textos didáticos diversos; diálogos acerca de dimensões do passado; o envolvimento com práticas culturais no âmbito da cultura escolar; debates acerca dos fazeres docentes

\footnotetext{
${ }^{14}$ Conforme facebook da escola, em postagem de 15 nov. 2012. Acesso em 10 mar. 2017.
} 
e discentes, tanto na sala de aula como em outros espaços da escola e lugares na/da cidade. Assim analisando, pode-se depreender dos dados e de nossas observações que, nesta escola, os jovens alunos tenderiam a atribuir sentidos críticos e, por vezes, tradicionais à História e, não menos importante, o sentido exemplar. Passamos, agora, a realizar movimento análogo com a escola pública central.

\section{A ESCOLA PÚBLICA CENTRAL}

Contemporaneamente, a escola pública central atende a múltiplas diversidades juvenis, compreendidas em seus aspectos territoriais, sociais e culturais. Considerada, no meio educacional, uma escola que oferece uma educação de qualidade e com grande inserção em movimentos sociais, políticos e culturais da cidade, oportuniza aos jovens estudantes variadas práticas sociais e culturais (DINIZ-FILHO, 2013). De acordo com este trabalho, nesta escola, existem algumas práticas culturais realizadas tanto pela direção e coordenação pedagógica, quanto pelos professores de História. Processo este corroborado pelas nossas observações exploratórias, sobretudo através de conversas informais junto a estudantes e lideranças do grêmio estudantil.

Assim pensando, supomos que estas experiências sensíveis, realizadas pelos jovens alunos do primeiro ano do Ensino Médio no seio da cultura escolar, oportunizam aproximações a aspectos de uma cultura histórica e política. Ou seja, seu agir no presente, instigados desde a sala de aula, pode oportunizar relações mais problematizadoras com as temporalidades históricas e, por vezes, estimular a um engajamento ponderado.

Diante disto, supomos haver uma tendência razoável à reflexividade e comunicabilidade entre estudantes, professores, direção e coordenação pedagógica desta escola, potencializando aspectos e discussões mais democráticas, abertas e sensíveis. Não obstante, permeados por tensões e contradições, por vezes de natureza interna, outras vezes relacionados a conflitos de variadas naturezas com os gestores públicos. Retomando as práticas culturais, em conversas informais junto a jovens estudantes desta escola, foi-nos relatado que os professores de História estimulam e 
mobilizam os educandos a visitar museus, a realizar pesquisas junto à rede mundial de computadores, a visitarem praças e outros lugares de memória da cidade.

Supomos, assim, que a professora de História desta escola também instigava os jovens estudantes a estas experiências e aprendizagens. Ao analisarmos a questão 13 (Questionário dos professores), trataremos mais deste processo. Vamos agora dialogar com os dados do Projeto Os Jovens e a História acerca desta escola, cotejando com nossas observações exploratórias, iniciando pela tabela 6 .

Tabela 6 - Questão 1 (Questionário dos alunos) - O que significa a História para você?

\begin{tabular}{|c|c|c|c|c|c|c|}
\hline & 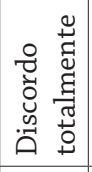 & 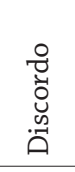 &  &  & 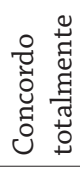 & 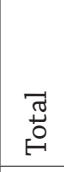 \\
\hline 1a. Uma matéria da escola e nada mais. & 61,5 & 15,4 & 15,4 & 0,0 & 7,7 & 100 \\
\hline $\begin{array}{l}\text { 1b. Uma fonte de coisas interessantes que } \\
\text { estimula minha imaginação. }\end{array}$ & 0,0 & 7,7 & 53,8 & 23,1 & 15,4 & 100 \\
\hline $\begin{array}{l}\text { 1c. Uma possibilidade para aprender com os erros } \\
\text { e acertos dos outros. }\end{array}$ & 0,0 & 0,0 & 38,5 & 53,8 & 7,7 & 100 \\
\hline $\begin{array}{l}\text { 1d. Algo que já morreu e passou e que não tem } \\
\text { nada a ver com a minha vida. }\end{array}$ & 38,5 & 38,5 & 7,7 & 7,7 & 7,7 & 100 \\
\hline $\begin{array}{l}\text { 1e. Um número de exemplos que ensinam o que é } \\
\text { certo e o que é errado, o que é bom e o que é mau. }\end{array}$ & 7,7 & 15,4 & 30,8 & 23,1 & 23,1 & 100 \\
\hline $\begin{array}{l}\text { 1f. Mostra o que está por trás da maneira de viver } \\
\text { no presente e explica os problemas atuais. }\end{array}$ & 7,7 & 0,0 & 30,8 & 30,8 & 30,8 & 100 \\
\hline 1g. Um amontoado de crueldades e desgraças. & 23,1 & 53,8 & 7,7 & 7,7 & 7,7 & 100 \\
\hline $\begin{array}{l}\text { 1h. Uma forma de entender a minha vida como } \\
\text { parte das mudanças na história. }\end{array}$ & 7,7 & 0,0 & 30,8 & 38,5 & 23,1 & 100 \\
\hline
\end{tabular}

Fonte: dados do Projeto Jovens e a História (2013). Elaborada pelos autores.

Na questão 1 (Questionário dos alunos) desta escola, destacamos as seguintes opções e suas tendências estatísticas: $1 \mathrm{~h}$ com Mais ou menos (30,8\%), Concordo (38,5\%), e Concordo totalmente (23,1\%); If com Mais ou menos (30,8\%), Concordo (30,8\%), e Concordo totalmente (30,8\%); 1c, Mais ou menos (38,5\%\%), Concordo (53,8\%), e Concordo totalmente (7,7\%). Levando em conta as variáveis estáticas destas opções, supomos poder apreender 
uma razoável tendência dos estudantes em atribuir, à História, um sentido de abertura às relações sócias e culturais mais amplas. Em outras palavras, aquilo que acontece em suas vidas apresenta alguma relação com aspectos sociais e culturais do seu entorno, conforme o próprio enunciado da opção 1h: Uma forma de entender a minha vida como parte das mudanças na História. Não é desprezível, nesta escola, o como demonstram os dados da opção 1e, conforme se pode observar na tabela 7, acima, acerca das dimensões dos exemplos. Desta atribuição de sentido à História, mais voltada à percepção dos alunos, vamos agora aos fazeres docentes manifestados na questão 13 (Questionário dos professores), pela professora ${ }^{15}$ de História desta escola, no momento em que respondeu à seguinte pergunta: $O$ que normalmente acontece em durante as aulas de História? Vale ressaltar que, excetuando a alternativa Quase nunca, essa professora de História marcou todas as outras, tendo em vista a pergunta dessa questão 13 (Questionário dos professores), e as opções apresentadas. Nesta questão, analisaremos aquilo que, segundo a docente, "normalmente acontece durante as aulas de história" (grifos nossos).

Assim, nesta questão, também levando em conta os significados atribuídos pelos jovens discentes, conforme já analisamos na tabela 7, aspectos de nossas observações e o trabalho de Diniz-Filho (2013), selecionamos as seguintes opções, com suas respectivas alternativas e escores percentuais: $13 \mathrm{a}$ (Os estudantes ouvem as minhas exposições sobre o passado), obtendo para as alternativas Frequentemente, 0,0\%; Quase sempre, 100,0\%; 13b (Os alunos são informados do que foi bom ou mau, certo ou errado na História), com Às vezes (0,0\%), Frequentemente (0,0\%), Quase sempre (100,0\%); $13 \mathrm{~g}$ (Eles usam livros escolares, apostilas ou algum outro material (fotocópia)), Às vezes (0,0\%), e Quase sempre (100,0\%). Agora, levando-se em conta, mais especificamente nossas observações e diálogos com a dissertação acima citada, escolhemos as seguintes outras opções, também com suas respectivas alternativas e medidas percentuais: 13c (Eles discutem diferentes explicações sobre o que aconteceu no passado), Às vezes $(100,0)$,

\footnotetext{
${ }^{15}$ A professora de História respondente deste questionário, em 2013, era designada. Esta é uma esta situação precária de trabalho (OLIVEIRA, 2004) que ainda persiste na rede estadual de Educação de Minas Gerais. Devido a esta situação, a docente de História não pode continuar seu trabalho nesta escola.
} 
Frequentemente (0,0\%), e Quase sempre (0,0\%); $13 \mathrm{f}$ (Eles ouvem fitas, cd's ou vemos filmes e vídeos sobre História), Às vezes (100,0), Frequentemente $(0,0 \%)$, e Quase sempre (0,0\%); e a $13 \mathrm{~h}$ (Eles participam de atividades em grupo: encenações de teatro, visitas a museus, projetos com a comunidade), Às vezes (0,0), Frequentemente (100,0\%), Quase sempre (0,0\%). Em certa medida, as respostas da professora desta escola possibilitam supor que seus fazeres em sala de aula estão implicados com aspectos dialógicos sobre tempos pretéritos e dimensões de "Um número de exemplos que ensinam [...]”. Elaborando certo exercício comparativo entre algumas opções desta questão 13 (Questionário dos professores) e a questão 1 (Questionário dos alunos) desta escola, supomos ser possível corroborar este movimento. Primeiro quanto a certo comparecimento de aspectos dialógicos acerca das discussões sobre o que aconteceu no passado. Compreendemos ser possível estabelecer certa relação entre a alternativa Às vezes, marcada pela docente de História na opção 13c (Eles discutem diferentes explicações sobre o que aconteceu no passado), e a tendência percentual manifesta nas seguintes alternativas da opção $1 \mathrm{~h}$ (Uma forma de entender a minha vida como parte das mudanças na história), com Mais ou menos (30,8\%), Concordo (38,5\%), e Concordo totalmente (23,1\%) e, de certa forma, ainda, na opção $1 \mathrm{f}$ (Mostra o que está por trás da maneira de viver no presente e explica os problemas atuais), com Mais ou menos (30,8\%), Concordo (30,8\%), e Concordo totalmente (30,8\%), ambas do questionário dos jovens alunos. Depois, acerca da dimensão dos “[...] exemplos que ensinam [...]", ao marcar, na opção 13b, (Os alunos são informados do que foi bom ou mau, certo ou errado na História), a alternativa Quase sempre, pode ser plausível pensar que este fazer da docente contribui, em alguma medida, para a tendência central na opção 1e (Um número de exemplos que ensinam o que é certo e o que é errado, o que é bom e o que é mau) do questionário dos alunos, manifesta nas alternativas Mais ou menos, com 30,8\%, Concordo $(23,1 \%)$ e Concordo totalmente (23,1\%), o que potencializa certo comparecimento de aspectos dos "exemplos que ensinam" nesta escola. Não menos importante é atentarmo-nos à alternativa Frequentemente, marcada na opção $13 \mathrm{~h}$ (Eles participam de atividades em grupo: encenações de teatro, visita a museus, projetos com a comunidade), e a alternativa Às vezes, marcada para a 
opção $13 f$ (Eles ouvem fitas, CD’s ou vemos filmes e vídeos sobre História). Supomos haver, por parte desta docente, uma atenção a explorar aspectos dos sentidos da História durante suas aulas; ou seja, o comparecimento das práticas culturais, potencializando a atribuição de sentidos à História. Novamente, reiteramos a fala, ainda que de maneira informal, enunciada para nós, enquanto realizamos nossas observações exploratórias na referida escola pública central, por uma jovem estudante do Ensino Médio, quanto ao incentivo e mobilização dos professores de História desta escola à visita a museus e outros lugares sensíveis da cidade. Desta forma, emergem reflexões acerca de tensões, contradições, afirmações e/ou continuidades, e outras dimensões sensíveis que estão comparecendo nos tempos atuais, ou na "história recente"16.

Tendo em vista o que auferimos acerca da percepção dos discentes sobre a História, dos fazeres da docente da disciplina, de nossas observações exploratórias e da pesquisa de Diniz-Filho (2013), realizada junto a esta escola, supomos que os jovens estudantes tenderiam a atribuir um sentido predominantemente mais crítico à História e, ainda, que apresentariam alguns diálogos no sentido exemplar; de modo menos importante, o comparecimento do sentido tradicional.

\section{POSSÍVEIS CONCLUSÕES...}

Nosso trabalho buscou analisar os sentidos da História atribuídos por jovens, em diálogo com aspectos de experiências de práticas culturais, emergentes na cultura escolar, oportunizadoras de apreensões de uma cultura histórica, aprendizados de uma cultura política de natureza democrática. Para tanto, fundamentamo-nos em trabalhos de Rüsen (2001; 2010; 2014), Pereira e Siman (2009), Faria filho e Vidal (2004), Moises (1992), e Abreu, Gontijo e Soihet (2007). Este estudo insere-se no projeto mais amplo, Os Jovens e a História, também realizado em cinco escolas de Belo Horizonte. Para nossa análise em profundidade, selecionamos uma

\footnotetext{
${ }^{16}$ Referência a um projeto, no campo da História, desenvolvido pelo pesquisador Luiz Fernando Cerri, disponível em um canal no youtube: <https://www.youtube.com/channel/ UCuppGdRLoDUEz3EVIdJEYBA>.
} 
escola pública da periferia e outra central por, dentre outros aspectos, pertencerem a uma mesma rede de ensino.

Para realizar esta análise, partimos do suposto que as práticas culturais possibilitam aos jovens estudantes vivenciarem experiências variadas, que contribuem tanto para a formação de uma predisposição à formação de uma cultura política de participação democrática, como para agirem temporalmente orientados. Para tanto, selecionamos a questão 1 (Questionário dos alunos) e a questão 13 (Questionário dos professores), e realizamos observações exploratórias junto às duas escolas escolhidas em Belo Horizonte, o que caracterizou uma abordagem predominantemente estatístico-descritiva.

Nossa análise mais ampla, abordando os dados estatísticos, tanto no Brasil quanto na cidade de Belo Horizonte, possibilitou depreender, das questões selecionadas do projeto, que os jovens alunos do primeiro ano do Ensino Médio, tanto no Brasil quanto em Belo Horizonte, tenderiam a atribuir sentidos críticos e, por vezes, tradicionais à História.

Quanto às duas escolas de Belo Horizonte analisadas mais verticalmente, também, como previsto, focamos nos dados da questão 1 (Questionário dos alunos) e aqueles da questão 13 (Questionário dos professores). De acordo com nossas observações exploratórias, os processos do ensinar e aprender História, desde a sala de aula até as experiências com as práticas culturais no interior da cultura escolar e em outros lugares educativos e sensíveis da cidade, potencializam, em alguma medida, a relação dos jovens alunos do primeiro ano do Ensino Médio com dimensões de uma cultura histórica e política. Essas experiências oportunizam aprendizado na relação com os outros, tanto individual como coletivamente, por vezes, através de exemplos, possibilitando levantamento de questões de variadas dimensões e naturezas. Desta forma, conforme já evidenciamos e analisamos neste trabalho, supomos comparecer a essas escolas o sentido crítico, dimensões do sentido tradicional, e não menos importante, o sentido exemplar. Não obstante, chamamos a atenção para certa diferença entre as tendências percentuais na opção 1c, referente à questão 1 (Questionário dos alunos); e 13b, referente à questão 13 (Questionário dos professores) das 
duas escolas. Na questão 1 (Questionário dos alunos), a opção 1c, na escola pública de periferia, a tendência percentual central fica com a alternativa Mais ou menos, obtendo 48,1\%; e na escola pública central, este movimento ocorre para a alternativa Concordo, obtendo 53,8\%. Em certa medida, esta diferença pode estar relacionada à alternativa Frequentemente, marcada pela professora da escola pública central na opção 13b, referente à questão 13 (Questionário dos professores), e a certa tradição de práticas culturais, debates coletivos experienciados por essa escola, desde a sala de aula de História. Isto pode levar a supor o comparecimento mais intenso da atribuição de sentido exemplar nesta escola. De outro lado, mas continuando com a questão 13 (Questionário dos professores), atentando-nos à alternativa Quase sempre, marcada na opção 13a; e a alternativa Frequentemente, para a opção 13g, hipoteticamente pensamos em processo análogo quando se trata, também, de atribuição do sentido tradicional pelos jovens alunos desta escola. Assim pensando, supomos que, nestas duas realidades escolares, haveria possíveis singularidades quanto à atribuição de sentidos à História pelos jovens estudantes do primeiro ano do Ensino Médio, sobretudo no que tange à atribuição de sentidos tradicionais e exemplar à História. Processos estes que demandam outras investigações.

De outro lado, agora, chamamos atenção para as potencialidades dos entrelaçamentos entre aspectos das culturas escolar, histórica e política, observadas exploratoriamente, sobretudo através das diferentes práticas culturais e políticas realizadas em cada uma das escolas analisadas em Belo Horizonte. De diferentes maneiras, supomos poder inferir que, em cada uma destas escolas, aquelas culturas estão vivas, pulsantes, potencialmente sensíveis, tanto a dimensões da vida prática, quanto às carências de orientação dos sujeitos estudantes do primeiro ano do Ensino Médio. Em alguns aspectos, isto pode ter potencializado dimensões da atribuição de sentidos à História. Em alguma medida, podem ser exemplo deste suposto dinamismo e interações entre cultura escolar, cultura histórica e cultura política, as diferentes práticas culturais realizadas em cada uma destas escolas, entre elas: na escola pública de periferia, visita a ocupações urbanas, os trabalhos com a comunidade e visitas a museus, tendo em vista contemplar aspectos da lei 11645/08 (BRASIL, 2008a). Na escola pública central, 
supomos poder inferir acerca das potencialidades dos fazeres docentes de História, visando a dinamizar as relações entre cultura escolar, histórica e política. Nesta direção, selecionamos, da questão 13 (Questionário dos professores), a opção 13h (Eles participam de atividades em grupo: encenações de teatro, visitas a museus, projetos com a comunidade), na qual a professora de História desta escola marcou a alternativa Frequentemente. O trabalho de Schimdt (2016b), até certo ponto, corrobora nossa inferência acerca destas potencialidades dos fazeres dos docentes de História, tendo em vista aqueles aspectos. É importante relembrar que estes processos também demandam aprofundamentos.

Outro aspecto a ser considerado, tendo em vista nosso trabalho, relaciona-se a um possível novo questionário do Projeto Os Jovens e a História. Ocorrendo este movimento, sugerimos explorar o comparecimento mais específico, sobretudo no que tange aos processos do ensinar e aprender História, das tecnologias da informação e comunicação na Educação (FERREIRA, 2010; TIMÓTEO, 2012) e dos jogos digitais (ARRUDA, 2009) quanto à atribuição de sentidos à História pelos jovens educandos do Ensino Médio. O trabalho de Timóteo (2012), entre outros aspectos, referenciando-se em Bakhtin (2009), oportuniza compreender que o conhecimento compartilhado pela rede tem o poder de dinamizar a alteridade e, desta forma, movimenta a engrenagem cognitiva, colocando em cena o exercício da palavra e da contra palavra, tão necessário ao processo de atribuição de sentido.

Por fim, entendemos ser importante aprofundar, em novas pesquisas, a apreensão e análise acerca dos sentidos atribuídos à História pelos jovens alunos do Ensino Médio por meio de suas narrativas em torno de alguma temática histórica, de maneira a buscar as relações entre as experiências culturais e políticas vivenciadas dentro e fora dos muros da escola.

\section{REFERÊNCIAS}

ABREU, M.; GONTIJO, R. SOIHET, R.; (Orgs.). Cultura politica e leituras do passado: historiografia e ensino de história. Rio de Janeiro: Civilização Brasileira/FAPERJ, 2007. 
ARRUDA, E. Jogos digitais e aprendizagens: o jogo Age of Empires III desenvolve ideias e raciocínios históricos de jovens jogadores? Brasil. 2010. Tese (Doutorado em Educação). PPGE/FAE/UFMG. Belo Horizonte. 2010. BARCA, I. A formação da consciência social dos jovens no horizonte da Educação Histórica. Educação, Santa Maria. v.37, n³, p.437-452. set./ dez. 2012.

BAROM, W. C. C. As publicações do projeto jovens e a história (2007-2014): metodologia, conceitos, temáticas, abordagens e algumas conclusões. História \& Ensino, Londrina, v. 22, n. 1, p. 71-90, jan. /jun. 2016.

BRASIL. Lei $\mathrm{n}^{\circ}$ 11.645, 10 de março de 2008a. Institui o ensino estudo da história e cultura afro-brasileira e indígena nas escolas de educação básica. Disponível em < http://portal.mec.gov.br/index. php?option=com_docman\&view=download\&alias=10101-lei-11645-1003-2008\&Itemid=30192> Acesso em 27/06/18.

BRASIL. Lei $\mathrm{n}^{\circ}$ 11.738, 10 de março de 2008b. Institui o piso nacional dos professores da educação básica e tempo de estudos. Disponível em <http://www.planalto.gov.br/ccivil_03/_ato2007-2010/2008/lei/111738. htm> Acesso em: 27/06/18.

CERRI, L. F. Ensino de história e Consciência Histórica: implicações didáticas de uma discussão contemporânea. Rio de Janeiro. FGV. 2011a.

. Cartografias Temporais: metodologias de pesquisa em consciência histórica. Educ. Real., Porto Alegre, v. 36, n.1, p. 59-81, jan./abr., 2011 b. . Canal História Recente. s.d. Disponível em: <https://www.youtube. com/channel/UCuppGdRLoDUEz3EVIdJEYBA >. Acesso em 27/06/18.

CERRI, L. F.; MOLAR, J. de O. Jovens diante da história: o nacional e o internacional na América Latina. Práxis Educativa, Ponta Grossa. v. 5, n², p.161-171, jul./dez. 2010.

CERRI, L. F.; AGUIRRE, M. C. Jovens e Sujeitos da História. Estudos IberoAmericanos. PUCRS, v. 37, nº1, p.125-140, jan./jun.2011. 
DINIZ-FILHO, M. A. Ensino de História e juventudes: a produção de sentidos no espaço escolar. 202f. Dissertação (Mestrado em Educação). PPGE/FAE/ UEMG. 2013.

E. E. Coração Eucarístico. - [Fotos de divulgação]. Disponível em: <https:// www.facebook.com/Escola-Estadual-Cora\%C3\%A7\%C3\%A3o-Eucar\%C3 \%ADstico-236743823086563/ >. Acesso em 10/03/17.

FARIA FILHO, L. M. de; VIDAL, D. G. A cultura escolar como categoria de análise e como campo de investigação na história da educação brasileira. Educação e Pesquisa, São Paulo, v.30, n.1, p. 139-159, jan. /abr. 2004.

FERREIRA, A. A. Desenvolvimento profissional de professores de história: estudo de caso de um grupo colaborativo mediado pelas tecnologias de informação e comunicação aplicadas à educação. Brasil. 2010. 260f. Tese (Doutorado em Educação). Programa de Pós-Graduação em Educação. FAE/UFMG. Belo Horizonte. 2010.

FORQUIN, J. C. Evoluções recentes do debate sobre escola, a cultura e as desigualdades na França. In: FRANCO, C. (Org.). Avaliação, ciclos e promoção na educação. Porto Alegre. Artmed. 2001. p. 101-120.

HELLER, A. Uma teoria da história. Rio de Janeiro. Civilização Brasileira. 1993.

HOBSBAWM, E. Era dos Extremos: o breve século XX: 1914 - 1991. São Paulo: Cia das Letras, 1995.

HOLLERBACH, J. D. G. O Jovem e o ensino de História: A construção da concepção de História por alunos do Ensino Médio. (Mestrado em Educação). Faculdade de Educação da Universidade Federal de Minas Gerais. 2007.

MIRANDA, S. R. Sob o signo da memória: cultura escolar, saberes docentes e história ensinada. São Paulo: Ed. da Unesp, 2007.

MIRANDA, S. R.; SIMAN, L. M. de C.; de (Orgs). Cidade, Memória e Educação. Juiz de Fora. UFJF. 2011.

MOISES, J. A. Democratização e cultura política de massa no Brasil. Lua nova, São Paulo, n. 26, p. 5-51, 1992. 
OLIVEIRA, D. A. A reestruturação do trabalho docente: precarização e flexibilização. Educação \& Sociedade. Campinas, vol. 25, n. 89, p. 11271144, set./dez. 2004.

PAIS, J. M. Consciência Histórica e Identidade: os jovens portugueses num contexto europeu. Oeiras: Celta. 1999.

PERREIRA, J. S.: SIMAN, L. M. de. Andarilhagens em Chão de Ladrilhos. In: FONSECA, Selva G. (Org.). Ensinar e Aprender História: formação, saberes e práticas educativas. Campinas. S.P. Alínea. 2009. p. 277-296.

PEREIRA, M. do C. O conhecimento tácito histórico dos adolescentes. Braga: Universidade do Minho, 2003.

RÜSEN, J. Razão Histórica: fundamentos da ciência histórica. Brasília. UNB. 2001.

RÜSEN, J. História Viva: teoria da História: formas e funções do conhecimento histórico. Brasília. UNB. 2010.

RÜSEN, J. Cultura Faz Sentido: orientações entre o ontem e o amanhã. R. J: Vozes, 2014.

SANTOS, M. O retorno do território. In: SANTOS, M.; SOUZA, M. A. A. de; SILVEIRA, M. L. (Org.). Território: globalização e fragmentação. São Paulo: HUCITEC/ANPUR, 1994. p. 11-14.

SCHIMDT, M. A. Jovens brasileiros, consciência histórica e vida prática. Revista História Hoje. V. 5, n9 9, p.31-48. 2016a.

. Aprendizagem e formação da Consciência Histórica: possibilidades de pesquisa em Educação Histórica. Educar em Revista, Curitiba. n60, p.17-42. abr./jun. 2016b.

SIMAN, L. M. de C. Práticas culturais e práticas escolares: aproximações e especificidades no ensino de história. História \& Ensino: Revista do Laboratório de Ensino de História, Londrina, v. 9, p.185-203, 2003.

TIMÓTEO, H. O. Caderno virtual: a potencialidade dos TICE no ensino e aprendizagem de história. 2012. 179 f. Dissertação (Mestrado em Educação) - PPGE/FAE/UEMG, 2012. 
TUAN, Y. Espaço e lugar: a perspectiva da experiência. São Paulo: Difel, 1983. TUTIAUX-GUILLON, N. Les questions socialmente vives, um repte per a la història i la geografia escolares? In: PAGÈS, J; SANTISTEBAN, A. Les questions socialmente vives i l'ensenuament de les ciències socials. Barcelona: UAB, 2011. p. 25-39.

WIKLUND, M. Além da racionalidade instrumental: sentido histórico e racionalidade na teoria da história de Jörn Rüsen. História da Historiografia. n. 1. p. 20-44, 2008. 